\title{
Free-Floating Iris Cyst in a Patient with Recurrent Iritis
}

\author{
Joanne M.Y. Teong ${ }^{a} \quad$ Paul A. Adler ${ }^{a}$ Dujon R.W. Fuzzard ${ }^{b}$ \\ ${ }^{a}$ Parke Street Specialist Centre, Katoomba, N.S.W., and ${ }^{b}$ Royal Victorian Eye and Ear \\ Hospital, East Melbourne, Vic., Australia
}

\section{Key Words}

Free-floating iris cyst $\cdot$ Anterior chamber $\cdot$ Iritis

\begin{abstract}
Purpose: We describe an unusual clinical finding of a free-floating iris cyst in a patient with recurrent iritis. Method: The clinical finding of a free-floating iris cyst was recorded using slitlamp photography. Results: A 39-year-old male with a 5-year history of recurrent right iritis was found to have a small mobile iris cyst within his right anterior chamber, first identified 3 years ago. The patient did not experience any discomfort or visual symptoms resulting from the cyst. Conclusion: Surgical removal is not indicated for asymptomatic non-progressive free-floating iris cysts. The significance of a free-floating iris cyst in the setting of recurrent iritis remains unknown.

(c) 2015 S. Karger AG, Basel
\end{abstract}

\section{Introduction}

A cyst is defined as an epithelial-lined space [1]. Primary cysts have no clear aetiology and tend to arise spontaneously, while secondary cysts result from a known aetiology such as trauma, surgery or medications $[1,2]$. Primary iris cysts may arise from either the iris pigment epithelium (IPE) or the iris stroma [2, 3]. In rare instances, an IPE cyst may dislodge and pass from the posterior chamber through the pupil, resulting in a free-floating cyst in the anterior chamber [1]. We describe such a case, where a free-floating iris cyst within the anterior chamber was observed in the setting of recurrent iritis. We also discuss the complications, significance of iritis and management of free-floating iris cysts. 
Teong et al.: Free-Floating Iris Cyst in a Patient with Recurrent Iritis

\section{Case Report}

A 39-year-old male with a 5-year history of mild recurrent iritis (6 episodes) affecting the right eye was found to have a free-floating iris cyst of approximately 0.5 by $0.8 \mathrm{~mm}$ within his right anterior chamber (fig. 1a). This was first identified 3 years ago after an episode of right iritis. The iris cyst did not cause any visual disturbance. Mobilisation of the cyst occurred with head tilt but never caused pain or visual compromise (fig. 1b). There were small fluctuations in the size of the iris cyst but no gross or rapid enlargement. His past medical history included reactive arthritis, and he tested positive for HLA-B27. There was no past history of ocular surgery or trauma, and no family history of ocular disease. The patient's visual acuity remained 6/5 in both eyes. His intraocular pressure ranged from 13 to $19 \mathrm{~mm} \mathrm{Hg}$. Gonioscopy showed an open anterior chamber angle in all quadrants. All episodes of mild iritis affected the anterior segment only and were treated effectively with dexamethasone ophthalmic drops for 2-6 weeks. He did not have keratic precipitates on his corneal endothelium, anterior or posterior synechiae. Serum biochemistry and inflammatory markers were within normal limits.

\section{Discussion}

Free-floating iris cysts comprise $<1 \%$ of primary IPE cysts [4]. The differential diagnosis includes iris stromal cyst, iris or ciliary body melanoma, adenoma of the IPE and medulloepithelioma [3]. Ultrasound biomicroscopy can be used to distinguish iris cysts from these uveal tumours [5]. IPE cysts have been associated with ocular complications such as angle closure glaucoma, plateau iris syndrome, and secondary pigment dispersion syndrome [6]. However, these complications are uncommon. A case series of 234 patients found that none of the IPE cysts grew larger after a mean follow-up period of 35 months. In particular, no visual or ocular complications were reported in patients with free-floating iris cysts [6].

Recurrent iritis in the setting of a mobile iris cyst is of uncertain significance. A study of 62 patients sought to determine current or prior ocular disorders associated with iris cysts $[1,7]$. Four patients had a history of iritis; however, ocular inflammation was either mild or in remission in 3 of the 4 patients [1, 7]. Only 1 patient presented with severe iritis and a large iris cyst, which regressed in size upon resolution of the iritis [1]. In another study of 14 patients with iritis, 3 patients showed evidence of new iris cyst formation [8]. This suggests that ocular inflammatory disorders may contribute to the development of iris cysts or cause pre-existing cysts to enlarge. However, the paucity of further evidence means that the full extent of this relationship remains theoretical. In our patient, the iris cyst was first identified after an episode of mild iritis. We could not find an association between the small fluctuations in the size of the iris cyst and his episodes of iritis.

Asymptomatic non-progressive iris cysts are best left alone, and the indications for surgical removal include significant visual disturbances, rapid increase in cyst size over a short period of time, evidence of recurrent iridocyclitis, corneal endothelial touch by the cyst or secondary glaucoma $[3,5]$. The use of neodymium-doped yttrium aluminium garnet laser to collapse the iris cyst has also shown favourable results in symptomatic patients $[3,9,10]$. Our patient remained asymptomatic; thus, surgical removal or laser treatment was not warranted. 
Teong et al.: Free-Floating Iris Cyst in a Patient with Recurrent Iritis

\section{Conclusion}

Free-floating iris cysts in the anterior chamber are an unusual clinical finding. Most remain stable without causing symptoms. Few have been implicated in causing visual disturbance or ocular complications, warranting their removal. The paucity of available evidence means that the association between recurrent iritis and the development or progression of free-floating iris cysts remains inconclusive.

\section{Statement of Ethics}

The patient's informed consent has been obtained.

\section{Disclosure Statement}

The authors have no competing or conflicts of interest to disclose.

\section{References}

1 Shields JA: Primary cysts of the iris. Trans Am Ophthalmol Soc 1981;79:771-809.

- Gurdeep S, Narendran K, Saravanan VR, Narendran V: Pigmented free-floating iris cysts. Br J Ophthalmol 2007;91:1037.

3 Rao A, Gupta V, Bhadange Y, Sharma R, Shields JA: Iris cysts: a review. Semin Ophthalmol 2011;26:11-22.

$\checkmark 4$ Shields CL, Shields PW, Manalac J, Jumroendararasame C, Shields JA: Review of cystic and solid tumors of the iris. Oman J Ophthalmol 2013;6:159-164.

5 Figus M, Ferretti C, Beneli U, Genovesi-Ebert F, Nardi M: Free-floating cyst in the anterior chamber: ultrasound biomicroscopic reports. Eur J Ophthalmol 2003;13:653-655.

6 Lois N, Shields CL, Shields JA, Mercado G: Primary cysts of the iris pigment epithelium: clinical features and natural course in 234 patients. Ophthalmology 1998;105:1879-1885.

7 Shields JA, Kline MW, Augsburger JJ: Primary iris cysts: a review of the literature and report of 62 cases. Br J Ophthalmol 1984;68:152-166.

-8 Gentile RC, Liebmann JM, Tello C, Stegman Z, Weissman SS, Ritch R: Ciliary body enlargement and cyst formation in uveitis. Br J Ophthalmol 1996;80:895-899.

-9 Onef HF, Kaynak S, Kocak N, Cingil G: Management of free floating iris cysts in the anterior chamber: a case report. Eur J Ophthalmol 2003;13:212-214.

$\rightarrow 10$ Baykara M, Sahin S, Erturk H: Free iris cyst in the anterior chamber. Ophthalmic Surg Lasers Imaging 2004;35:74-75. 
Case Reports in

Ophthalmology
Case Rep Ophthalmol 2015;6:176-179

DOI: $10.1159 / 000432393$

C 2015 S. Karger AG, Basel

www.karger.com/cop

Teong et al.: Free-Floating Iris Cyst in a Patient with Recurrent Iritis
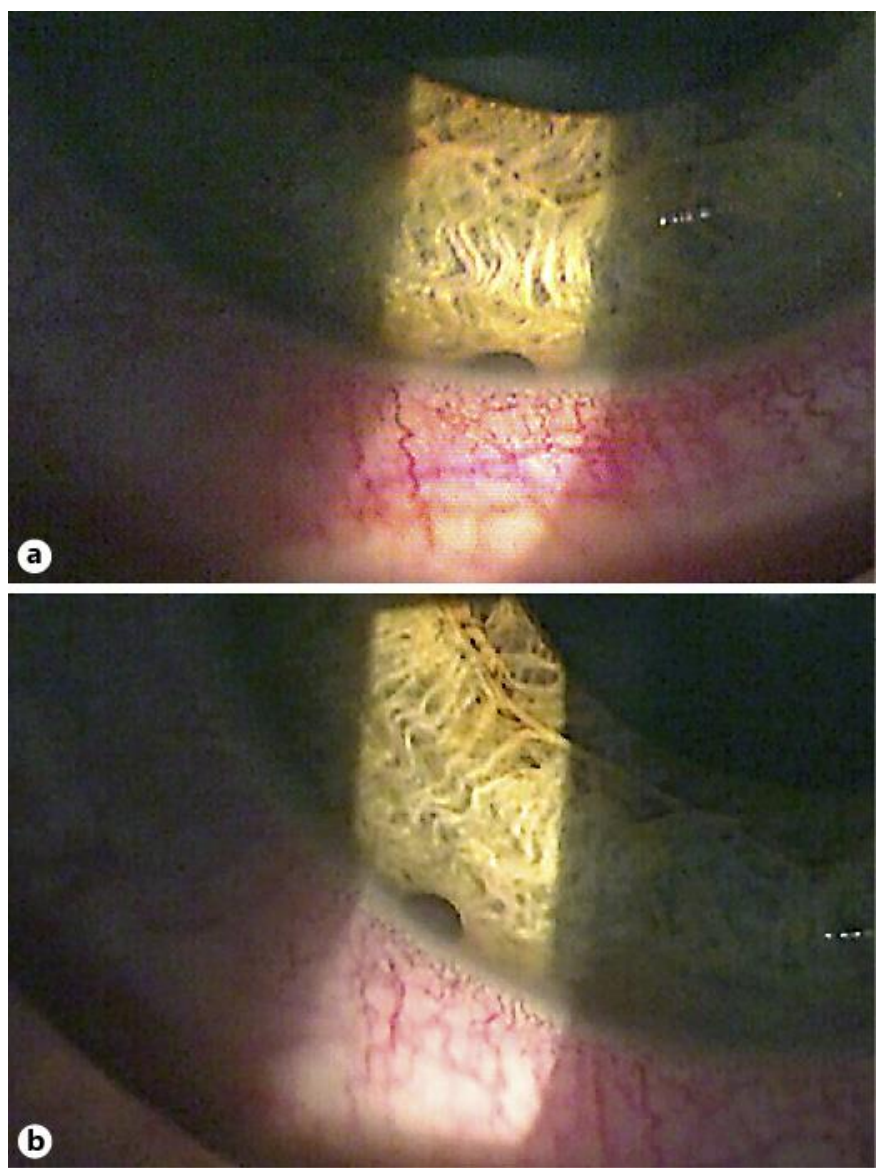

Fig. 1. a Free-floating iris cyst in the anterior chamber (primary gaze). b Mobilisation of the iris cyst with head tilt. 